from the study if they had received anticoagulant therapy or had undergone carotid revascularization. However, differences aside, the lesson from TIAregistry.org should not be that we have solved the problem of acute recurrent ischemia, but rather that we must redouble our efforts to treat patients before these early recurrent events can occur. In addition, the search for effective interventions must continue.

Anthony S. Kim, M.D.

J. Donald Easton, M.D.

University of California, San Francisco

San Francisco, CA

akim@ucsf.edu

S. Claiborne Johnston, M.D., Ph.D.

Dell Medical School

Austin, TX

Dr. Easton reports receiving grant support and consulting fees from AstraZeneca and consulting fees from Boehringer Ingelheim and Bristol-Myers Squibb; and Drs. Easton and Johnston, receiving grant support through their institution from AstraZeneca. No other potential conflict of interest relevant to this letter was reported.

1. Amarenco P, Lavallée PC, Labreuche J, et al. One-year risk of stroke after transient ischemic attack or minor stroke. $\mathrm{N}$ Engl J Med 2016;374:1533-42.

2. Wang $\mathrm{Y}$, Wang $\mathrm{Y}$, Zhao X, et al. Clopidogrel with aspirin in acute minor stroke or transient ischemic attack. N Engl J Med 2013;369:11-9.

3. Johnston SC, Amarenco P, Albers GW, et al. Ticagrelor versus aspirin in acute stroke or transient ischemic attack. N Engl J Med 2016;375:35-43.

DOI: 10.1056/NEJMc1606657

THE AUTHOR REPLIES: Differences in 90-day stroke risks probably reflect differences between routine clinical practice in TIA clinics in Europe, Asia, and Latin America that included all patients with a TIA and clinical trials that purposely selected high-risk patients. ${ }^{1,2}$ These differences also reflect variations in the provision of care throughout the world because of economic differences.

In the trial by Wang et al., ${ }^{1}$ which was performed in China, only half the patients with hypertension received a blood-pressure-lowering agent and half the patients with diabetes received an antidiabetic drug during the follow-up period (Table S3 in the Supplementary Appendix, available with the full text of the article by Wang et al. at NEJM.org). Risk-factor control was probably even worse before the index event than after the index event, and this most likely contributed to the very high rate of stroke (11.7\%) at 90 days. ${ }^{1}$ In the ticagrelor trial, ${ }^{2}$ the overall $5.9 \%$ stroke risk at 90 days was partly driven by an $11.5 \%$ risk among patients from Asia and Australia and by only a $5.2 \%$ risk among patients in North America.

Current available evidence suggests that health authorities should develop TIA clinics to immediately assess the cause of the TIA and start treatment. We agree that there is still room for improvement, particularly in acute antithrombotic therapy.

Pierre Amarenco, M.D.

Paris-Diderot Sorbonne University

Paris, France

pierre.amarenco@aphp.fr

for the Steering Committee

Investigators of the TIAregistry.org

Since publication of his article, the author reports no further potential conflict of interest.

1. Wang Y, Wang Y, Zhao X, et al. Clopidogrel with aspirin in acute minor stroke or transient ischemic attack. N Engl J Med 2013;369:11-9.

2. Johnston SC, Amarenco P, Albers GW, et al. Ticagrelor versus aspirin in acute stroke or transient ischemic attack. N Engl J Med 2016;375:35-43.

DOI: 10.1056/NEJMc1606657

\title{
Colorectal Adenomas
}

TO THE EDITOR: In his review article, Strum (March 17 issue) ${ }^{1}$ provides data on the overall prevalence of colorectal adenomas in the United States and risk factors for these lesions. It is well established that patients with Streptococcus bovis-group infective endocarditis are at high risk for colorectal cancer. ${ }^{2}$ Although a strong relationship between Enterococcus faecalis endocarditis and colorectal adenomas is suspected, robust data are lacking.
Of the 150 patients with a diagnosis of enterococcal endocarditis in our cohort from 1979 through 2013, a total of 108 had E. faecalis endocarditis of unknown origin. Of these patients, 58 (54\%) underwent colonoscopy at admission. A total of 44 patients $(76 \%)$ received a new diagnosis of colonic disease, including colorectal adenoma in 20 patients (34\%) and colorectal cancer in 5 (9\%) (1 patient received a diagnosis dur- 
ing the first year of follow-up). ${ }^{3}$ This prevalence is similar to that of colorectal adenoma and 17 times as high as that of colorectal cancer among patients who were screened with the use of colonoscopy in a study by Quintero et al. ${ }^{4}$ Although data are lacking to confirm these findings, attention must be paid to the relationship between E. faecalis endocarditis and colorectal cancer.

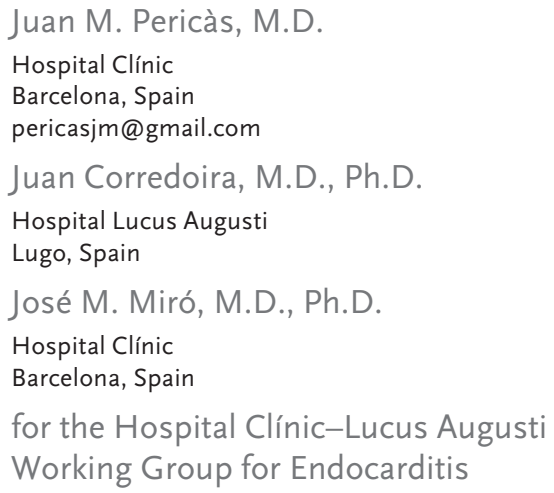

No potential conflict of interest relevant to this letter was reported.

1. Strum WB. Colorectal adenomas. N Engl J Med 2016;374: 1065-75.

2. Klein RS, Recco RA, Catalano MT, Edberg SC, Casey JI, Steigbigel NH. Association of Streptococcus bovis with carcinoma of the colon. N Engl J Med 1977;297:800-2.

3. Pericàs JM, Corredoira J, Moreno A, et al. Should all patients with Enterococcus faecalis endocarditis undergo a colonoscopy? (Communication P0027.) Presented at the 13th International Symposium on Modern Concepts in Endocarditis and Cardiovascular Infections, Rio de Janeiro, June 4-6, 2015.

4. Quintero E, Castells A, Bujanda L, et al. Colonoscopy versus fecal immunochemical testing in colorectal-cancer screening. N Engl J Med 2012;366:697-706.

DOI: 10.1056/NEJMc1604867

TO THE EDITOR: In his review article on colorectal adenomas, Strum states that stool DNA tests were only moderately sensitive for cancer. However, the observed 92 to $100 \%$ detection rates have been very high in stool DNA screening studies (Fig. 1A) ) $^{1,2}$ and rival reported detection rates in colonoscopy. Moreover, Table 3 of the article contained errors; data on cancer detection by means of the stool DNA test and the fecal immunochemical test (FIT) were reversed, and the statistical comparison of rates of lesion detection between the stool test and colonoscopy is invalid because the latter was the reference standard.

Small adenomas were discussed extensively, but most do not progress. Since most high-grade dysplasia occurs in polyps that are larger than 2 $\mathrm{cm}$ in diameter, ${ }^{3}$ detection of these highest-risk

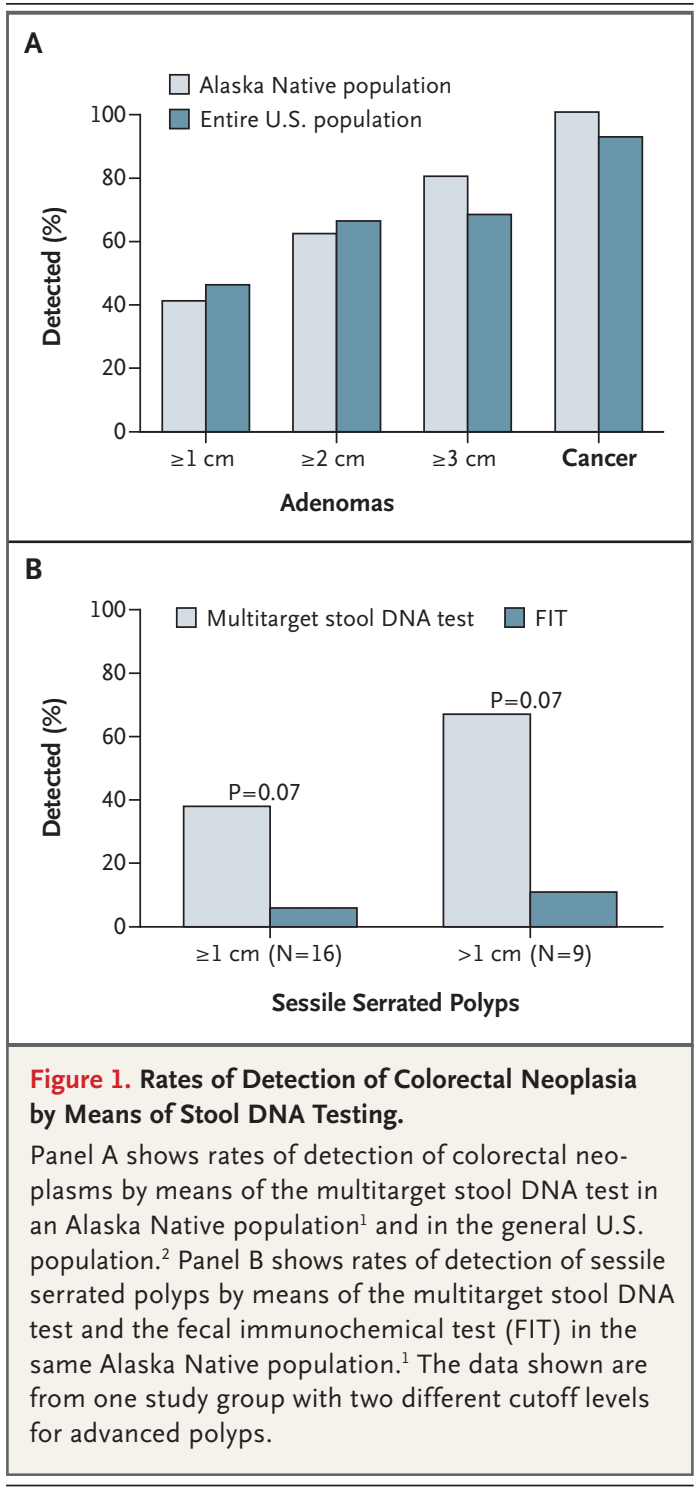

large polyps has a greater effect on cancer prevention than does detection of smaller polyps. The screening sensitivity of the stool DNA test increases with the size of the adenoma (Fig. 1A). ${ }^{1,2}$ Consequently, at the recommended frequency of every 3 years, the estimated screeningprogram sensitivity of the stool DNA test for high-grade dysplasia exceeds $90 \%$ by the second screening round ${ }^{4}$; this rate compares favorably with that of colonoscopy every 10 years. Moreover, the stool DNA test detects most sessile serrated polyps that are larger than $1 \mathrm{~cm}$ in diameter. ${ }^{1,2}$ These nonhemorrhagic lesions are rarely detected by means of FIT (Fig. 1B) and are often overlooked on colonoscopy. 
Steven H. Itzkowitz, M.D.

Icahn School of Medicine

New York, NY

David A. Ahlquist, M.D.

Mayo Clinic

Rochester, MN

Dr. Itzkowitz reports receiving fees for serving on the scientific advisory board for and being a research collaborator with Exact Sciences; and Dr. Ahlquist, being a co-inventor of the stool DNA test Cologuard, sharing royalties to Mayo Clinic from Exact Sciences in accordance with institutional policy, and receiving fees for serving as a scientific advisor to and research collaborator with Exact Sciences. No other potential conflict of interest relevant to this letter was reported.

1. Redwood DG, Asay ED, Blake ID, et al. Stool DNA testing for screening detection of colorectal neoplasia in Alaska Native people. Mayo Clin Proc 2016;91:61-70.

2. Imperiale TF, Ransohoff $\mathrm{DF}$, Itzkowitz $\mathrm{SH}$, et al. Multitarget stool DNA testing for colorectal-cancer screening. N Engl J Med 2014;370:1287-97.

3. Pickhardt PJ, Hain KS, Kim DH, Hassan C. Low rates of cancer or high-grade dysplasia in colorectal polyps collected from computed tomography colonography screening. Clin Gastroenterol Hepatol 2010;8:610-5.

4. Ahlquist DA. Multi-target stool DNA test: a new high bar for noninvasive screening. Dig Dis Sci 2015;60:623-33.

DOI: 10.1056/NEJMc1604867

TO THE EDITOR: Strum covers the topic of colorectal adenomas in great detail. However, the importance of genetic syndromes as a cause of colorectal adenomas was underemphasized. Although, as stated, a family history of colorectal adenomas is associated with an increased risk of the disease, uncovering the genetic cause of the disease can help clinicians to adjust the screening pattern according to the mutation status and family history and can lead to a more personalized screening plan. In addition, other at-risk persons can be identified.

Since APC mutations were associated with colorectal adenomas in 1991, mutations in many other genes have been strongly associated with these tumors. Specific histologic types of polyps have been linked to these genes. For example, conventional adenomas have been associated with monoallelic mutations in POLE, POLD1, and FOCAD, and with biallelic mutations in MUTYH, MLH1, MSH2, MSH6, PMS2, and NTHL1. Juvenile polyps have been linked to SMAD4 and BMPR1A, PeutzJeghers polyps to STK11, hamartomas to PTEN, and mixed polyps to GREM1. ${ }^{1-3}$ Combining the patient's age at the onset of the polyps and their pathological subtype with genetic testing and family history can help the clinician to most effectively treat the patient.
Ester Castellsagué, Ph.D.

Barbara Rivera, Ph.D.

William D. Foulkes, M.B., B.S., Ph.D.

McGill University

Montreal, QC, Canada

william.foulkes@mcgill.ca

No potential conflict of interest relevant to this letter was reported.

1. Valle L. Genetic predisposition to colorectal cancer: where we stand and future perspectives. World J Gastroenterol 2014; 20:9828-49.

2. Tomlinson I. The Mendelian colorectal cancer syndromes. Ann Clin Biochem 2015;52:690-2.

3. Horpaopan S, Spier I, Zink AM, et al. Genome-wide CNV analysis in 221 unrelated patients and targeted high-throughput sequencing reveal novel causative candidate genes for colorectal adenomatous polyposis. Int J Cancer 2015;136(6):E578-89.

DOI: 10.1056/NEJMc1604867

THe AUthors Reply: Pericàs et al. point out the association between $S$. bovis and E. faecalis and colorectal cancer. Itzkowitz and Ahlquist indicate that most small adenomas do not progress, that most high-grade dysplasia occurs in polyps that are $20 \mathrm{~mm}$ in diameter or larger, and that the sensitivity of the stool DNA test increases with the size of the adenoma. It is not clear whether Itzkowitz and Ahlquist propose to discount the clinical significance of adenomas that are smaller than $20 \mathrm{~mm}$ in diameter; if so, the detection rates with stool DNA screening could reach 60 to $80 \%$.

I have several concerns. First, experts in the field indicate that discovery and removal of small precancerous adenomas that are larger than $5 \mathrm{~mm}$ in diameter are relevant objectives of screening and prevention. ${ }^{1}$ Second, the most clinically significant cutoff value in use for the size of polyps is $9 \mathrm{~mm}$ in diameter, and this value has additional relevance in computed tomographic colonography because colonographers do not routinely recommend removal of all polyps that are smaller than $10 \mathrm{~mm}$ in diameter. ${ }^{1}$ Third, increasing sensitivity in detecting adenomas as they increase in size is not unique to the stool DNA test.

Part of the purpose of my article was to highlight the wide variance in pathological importance depending on the size of the lesion. Advanced adenoma status is attributed to $1.1 \%$ of diminutive polyps and $1.3 \%$ of small polyps, whereas this status is attributed to $13.2 \%$ of large polyps. An improved definition of advanced adenomas might be those that are larger than $9 \mathrm{~mm}$ in diameter and contain high-grade 
dysplasia or villous architecture, rather than tubulovillous architecture.

The inadvertent reversal of data on cancer detection by the stool DNA test and FIT in Table 3 of my article notwithstanding, the thrust of the message of Table 3 is that stool-based tests for advanced adenoma do not fare well as compared with colonoscopy; this has been adroitly shown to be valid in the studies by Imperiale et al. and Quintero et al. (cited as references 5 and 61 in my article, respectively). The assumption by Itzkowitz and Ahlquist that stool DNA testing might reach a sensitivity of $90 \%$ by a second round of screening at 3 years is an estimated outcome that has not been proved. Stool DNA testing is an appealing approach to screening, but it involves several obstacles, ${ }^{2}$ including costineffectiveness, since a positive test requires colonoscopy as a second procedure., ${ }^{3,4}$

Castellsagué and colleagues note mutations that are associated with colon-cancer syndromes.
Although a discussion of genetic syndromes was not a goal of my article, these mutations were noted in a reference to an article by Stoffel and Boland (cited as reference 15 in my article).

Williamson B. Strum, M.D.

Scripps Clinic Medical Group

La Jolla, CA

fstrum@aol.com

Since publication of his article, the author reports no further potential conflict of interest.

1. Levin B, Lieberman DA, McFarland B, et al. Screening and surveillance for the early detection of colorectal cancer and adenomatous polyps, 2008: a joint guideline from the American Cancer Society, the US Multi-Society Task Force on Colorectal Cancer, and the American College of Radiology. Gastroenterology 2008;134:1570-95.

2. Robertson DJ, Dominitz JA. Stool DNA and colorectal-cancer screening. N Engl J Med 2014;370:1350-1.

3. Lansdorp-Vogelaar I, Kuntz KM, Knudsen AB, Wilschut JA, Zauber AG, van Ballegooijen M. Stool DNA testing to screen for colorectal cancer in the Medicare population: a cost-effectiveness analysis. Ann Intern Med 2010;153:368-77.

4. Robertson DJ, Imperiale TF. Stool testing for colorectal cancer screening. Gastroenterology 2015;149:1286-93.

DOI: $10.1056 /$ NEJMc1604867

\section{Point-of-Care Warfarin Monitoring in the ROCKET AF Trial}

TO THE EDITOR: On February 5, 2016, the European Medicines Agency (EMA) released an assessment report on rivaroxaban (Xarelto), in which it described Bayer's comparison of the international normalized ratio (INR) values obtained by the Alere INRatio Monitor System (formally known as the Hemosense INRatio device) and those obtained by a central laboratory on samples collected at weeks 12 and 24 during the ROCKET AF trial. ${ }^{1}$ Although the point-of-care device reported lower INR values than those shown by the laboratory results, the error was not influenced by either anemia or conditions causing elevated fibrinogen levels. Since this finding negates the fundamental assumption in the post hoc analysis of the ROCKET AF data by Patel et al., ${ }^{2}$ how should their results be interpreted? Of the 767 central-laboratory samples with an INR of more than 4 at week 12, the point-of-care device reported values of less than 3 for 219 samples (29\%). ${ }^{1}$ Although the EMA found insufficient evidence to alter the benefit-risk conclusion of the original rivaroxaban study, the agency did not address several important questions. How many warfarin-treated patients had major bleeding as a result of this error in the point-of-care device? Did this error result in a change in the percentage of time that patients receiving warfarin were in the therapeutic range? Answers to these questions could alter the relative benefitrisk relationship between rivaroxaban and warfarin. They could also diminish the validity of the ROCKET AF study. ${ }^{3}$

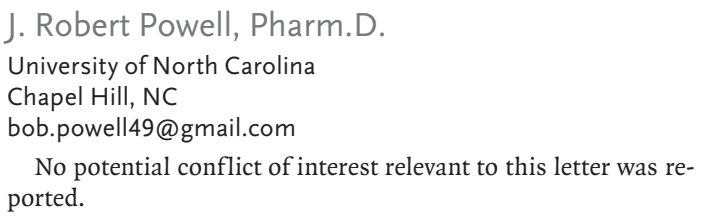

No potential conflict of interest relevant to this letter was reported.

1. European Medicines Agency assessment report: Xarelto. February 5, 2016 (http://www.ema.europa.eu/docs/en_GB/document _library/EPAR__Assessment_Report_-_Variation/human/000944/ WC500201726.pdf)

2. Patel MR, Hellkamp AS, Fox KAA. Point-of-care warfarin monitoring in the ROCKET AF trial. N Engl J Med 2016;374:785-8. 3. Patel MR, Mahaffey $\mathrm{KW}$, Garg J, et al. Rivaroxaban versus warfarin in nonvalvular atrial fibrillation. N Engl J Med 2011; 365:883-91.

DOI: $10.1056 /$ NEJMc1604020

THE AUTHORS REPLY: In response to the comments of Powell and to provide further insight, we now present the results of additional analyses using central-laboratory INR measurements on 